\title{
The association of leptin with severity of non-alcoholic fatty liver disease: A population-based study
}

\author{
Laura Rotundo', Alana Persaud', Mirela Feurdean', Sushil Ahlawat ${ }^{2}$, and Hyun-seok Kim ${ }^{1,3}$ \\ 'Department of Medicine, and 2Division of Gastroenterology and Hepatology, Rutgers New Jersey Medical School, Newark, NJ; \\ ${ }^{3}$ Section of Gastroenterology and Hepatology, Baylor College of Medicine, Houston, TX, USA
}

Background/Aims: Leptin is associated with metabolic disorders, which predispose one to non-alcoholic fatty liver disease (NAFLD). The role of leptin in NAFLD pathogenesis is not fully understood. We aim to investigate the association between serum leptin level and severity of NAFLD using U.S. nationally representative data.

Methods: Data were obtained from the United States Third National Health and Nutrition Examination Survey. NAFLD was defined by ultrasound detection and severity of hepatic steatosis in the absence of other liver diseases. The severity of hepatic fibrosis was determined by NAFLD fibrosis score (NFS). We used multivariate survey-weighted generalized logistic regression to evaluate the association between leptin level and the degree of NAFLD. We also performed subgroup analyses by body mass index (lean vs. classic NAFLD).

Results: Among 4,571 people, 1,610 (35\%) had NAFLD. By ultrasound findings, there were 621 people with mild, 664 with moderate, and 325 with severe steatosis. There were 885 people with low NFS $(<-1.455$, no significant fibrosis), 596 with intermediate NFS, and 129 with high NFS ( $>0.676$, advanced fibrosis). Leptin levels for normal, mild, moderate and severe steatosis were $10.7 \pm 0.3 \mathrm{ng} / \mathrm{mL}, 12.1 \pm 0.7 \mathrm{ng} / \mathrm{mL}, 15.6 \pm 0.8 \mathrm{ng} / \mathrm{mL}, 16 \pm 1.0 \mathrm{ng} / \mathrm{mL}$, respectively (trend $P$-value $<0.001$ ). Leptin levels for low, intermediate, and high NFS were $11.8 \pm 0.5 \mathrm{ng} / \mathrm{mL}, 15.6 \pm 0.8 \mathrm{ng} / \mathrm{mL}, 28.5 \pm 3.5 \mathrm{ng} / \mathrm{mL}$, respectively (trend $P$-value $<0.001$ ). This association remained significant even after adjusting for known demographic and metabolic risk factors. In the subgroup analysis, this association was only prominent in classic NAFLD, but not in lean NAFLD.

Conclusions: Serum leptin level is associated with the severity of NAFLD, especially in classic NAFLD patients.

(Clin Mol Hepatol 2018;24:392-401)

Keywords: Non-alcoholic fatty liver disease; Leptin; Fibrosis

\section{Abbreviations:}

NAFLD, non-alcoholic fatty liver disease; NFS, non-alcoholic fatty liver disease fibrosis score; NHANES, National Health and Nutrition Examination Survey
Corresponding author: Hyun-seok Kim

Section of Gastroenterology and Hepatology, Baylor College of Medicine, 1 Baylor Plaza, Houston, TX 77030, USA

Tel: +1-713-798-0950, Fax:+1-713-798-0223

E-mail:bhsk0036@gmail.com

https://orcid.org/0000-0002-0376-0836

\section{Laura Rotundo}

Department of Medicine, Rutgers New Jersey Medical School, 150 Bergen Street, UH I-248, Newark, NJ 07101, USA

Tel: +1-973-972-6056, Fax:+1-973-972-3129

E-mail: sahyoulc@njms.rutgers.edu

https://orcid.org/0000-0002-4094-3682 


\section{Study Highlights}

This study investigated the association of serum leptin level and the degree of non-alcoholic fatty liver disease (NAFLD) based both ultrasound findings and NAFLD fibrosis score. Serum leptin level is significantly associated with the severity of NAFLD, even accounting for potential confounders. This association is especially prominent among the classic NAFLD patients (body mass index [BMI] >30), which suggest that leptin's role in NAFLD pathogenesis may be BMl-dependent.

\section{INTRODUCTION}

Leptin, the product of the ob gene, regulates energy homeostasis, as well as glucose and lipid metabolism. ${ }^{1}$ There has been increasing evidence on leptin's role in metabolic disorders, with elevated leptin levels seen in metabolic syndrome, obesity, and diabetes mellitus. ${ }^{2}$ Leptin is thought to increase insulin resistance and increased fatty acid production in hepatocytes ${ }^{3}$ as well as result in increased oxidative stress ${ }^{4}$ and inflammatory and fibrogenic pathways in the liver. ${ }^{5,6}$

Currently, non-alcoholic fatty liver disease (NAFLD) is emerging as one of the leading causes of chronic liver disease in the United States with approximately 20 to $30 \%$ of the general population affected and is considered a liver manifestation of metabolic syndrome. ${ }^{7,8}$ The prevalence of NAFLD increases to two-thirds in obese individuals and is present in over $90 \%$ of those with class III obesity. ${ }^{9}$ While the majority of NAFLD patients are obese, there is increasing attention on lean individuals with NAFLD, ${ }^{10}$ which may represent a clinical entity with discrete characteristics and prognosis. Lean NAFLD patients also tend to have increased rates of insulin resistance, central obesity, hypertriglyceridemia and hyperuricemia when compared to those without fatty liver." A prior study has suggested that lean NAFLD may have a worse survival prognosis than classic NAFLD. ${ }^{12}$

Although a few studies have reported the possible role of leptin in the pathogenesis of NAFLD, these studies evaluated a small patient population at a single institution ${ }^{13,14}$ or in animal models, ${ }^{6,15,16}$ and the findings are inconsistent over whether leptin levels affect the severity of NAFLD. ${ }^{17-19}$ To our knowledge, there is no published United States population-based study that investigates the association of leptin with NAFLD. Ikejima et al. ${ }^{5}$ investigated using rat models treated with carbon tetrachloride, and found that leptin may contribute to the pathogenesis of NAFLD via increased expression of procollagen-I, transforming growth factor B1, and activation of hepatic stellate cells leading to fibrosis. However, other studies ${ }^{17-19}$ have shown that leptin is associated only with the degree of steatosis but not with fibrosis. Thus, it would be important to investigate the association of serum leptin levels with demographic and metabolic risk factors as well as whether it correlates with the degree of NAFLD and if this correlation differs among lean versus classic NAFLD, using nationally representative data in the United States.

\section{MATERIALS AND METHODS}

\section{NHANES}

The Third National Health and Nutrition Examination Survey (NHANES III) is a population-based cross-sectional survey that includes the non-institutionalized, civilian population in the United States conducted from 1988 through 1994. The survey is conducted in 2-year cycles through the National Center for Health Statistics of the Centers for Disease Control and Prevention. The survey uses a stratified, multistage probability sampling design with information generated from household interviews, physical examinations and biological testing. Further information of survey design can be found elsewhere. ${ }^{20}$ The Centers for Disease Control and Prevention's Institutional Review Board approved the original survey. All participates gave written informed consent.

\section{Study population}

Study participants were included in our analysis if they met the selection criteria as follows: aged 20 to 74 years old with available selected clinical and laboratory variables as mentioned in covariate section below as well as liver ultrasound data. Those with other potential causes of liver diseases were excluded from the study: heavy alcohol consumption ( $\geq 21$ drinks/week in men and $\geq 14$ drinks/week in women), viral hepatitis (indicated by a positive serum hepatitis $B$ surface antigen or serum hepatitis $C$ antibody), iron overload (transferrin saturation $\geq 50 \%$ ), or pregnancy. After the selection process, 4,571 people were included in this study (Fig. 1). 


\section{Definition of NAFLD}

NHANES III examination included ultrasonography of the liver and gallbladder at mobile examination centers as part of the assessment for digestive diseases in adults aged 20 to 74 years. Afterwards, these ultrasound images were reviewed for signs of fatty liver. ${ }^{21} \mathrm{~A}$ board-certified radiologist that specialized in hepatic imaging trained three ultrasound reviewers that studied the collected images. Five criteria were used to evaluate for fatty liver: parenchymal brightness, liver-to-kidney contrast, deep beam attenuation, bright vessel walls, and gallbladder wall definition. An algorithm with these five criteria was used to generate an overall assessment of normal compared to mild, moderate or severe hepatic steatosis. ${ }^{20}$ NAFLD was defined by ultrasonography detection of hepatic steatosis in the absence of other known liver diseases and categorized as normal, mild, moderate, or severe. The severity of hepatic fibrosis was determined by NAFLD fibrosis score (NFS). ${ }^{22}$

NFS $=-1.675+0.037 \times$ age $($ years $)+0.094 \times$ body mass index $(\mathrm{BMI})\left(\mathrm{kg} / \mathrm{m}^{2}\right)+1.13 \times$ impaired fasting glycemia or diabetes (yes $=1$, no $=0)+0.99 \times$ aspartate aminotransferase (AST)/alanine aminotransferase (ALT) $-0.013 \times$ platelet $(\times 109 / \mathrm{L})-0.66 \times$ albumin $(\mathrm{g} / \mathrm{dL})$

Two cutoff values were selected to categorize subjects with NAFLD into three groups: those with high probability (NFS
$>0.676$ ), intermediate probability (NFS 0.676 to -1.455 ) and low probability for fibrosis (NFS $\leq-1.455$ ).

To confirm our findings, we also performed analyses to investigate the association between AST to platelet ratio index (APRI) $\mathrm{score}^{23}$ and leptin levels. Two cut-off values were used to categorize NAFLD patients (APRI score <0.7: low APRI, APRI score 0.72.0: intermediate APRI, and APRI score $>2.0$ : high APRI).

\section{Clinical and laboratory data}

The NHANES data set provides a large amount of demographic data, lifestyle and dietary information, and anthropometric as well as inclusive laboratory measurements. ${ }^{24,25}$ Waist circumference was measured during a health examination in the Mobile Examination Center (MEC) and was measured at the highest point of the iliac crest at minimal respiration. BMI $\left(\mathrm{kg} / \mathrm{m}^{2}\right)$ was categorized as: normal $(<25.0)$, overweight (25.0-29.9), obese ( $\geq 30.0)$. Systolic blood pressures (SBP) and diastolic blood pressures (DBP) were measured in the MEC after participants rested for 5 minutes quietly in a sitting position and after determining maximum inflation level. Hypertension was defined if the systolic blood pressure was greater or equal to $140 \mathrm{mmHg}$ or diastolic blood pressure greater or equal to $90 \mathrm{mmHg}$ and/or a self-reported hypertension diagnosis was present. Diabetes mellitus was defined as those with a history of diabetes diagnosis and/or treatment with hypoglycemic agents, including insulin. Insulin resistance was based on

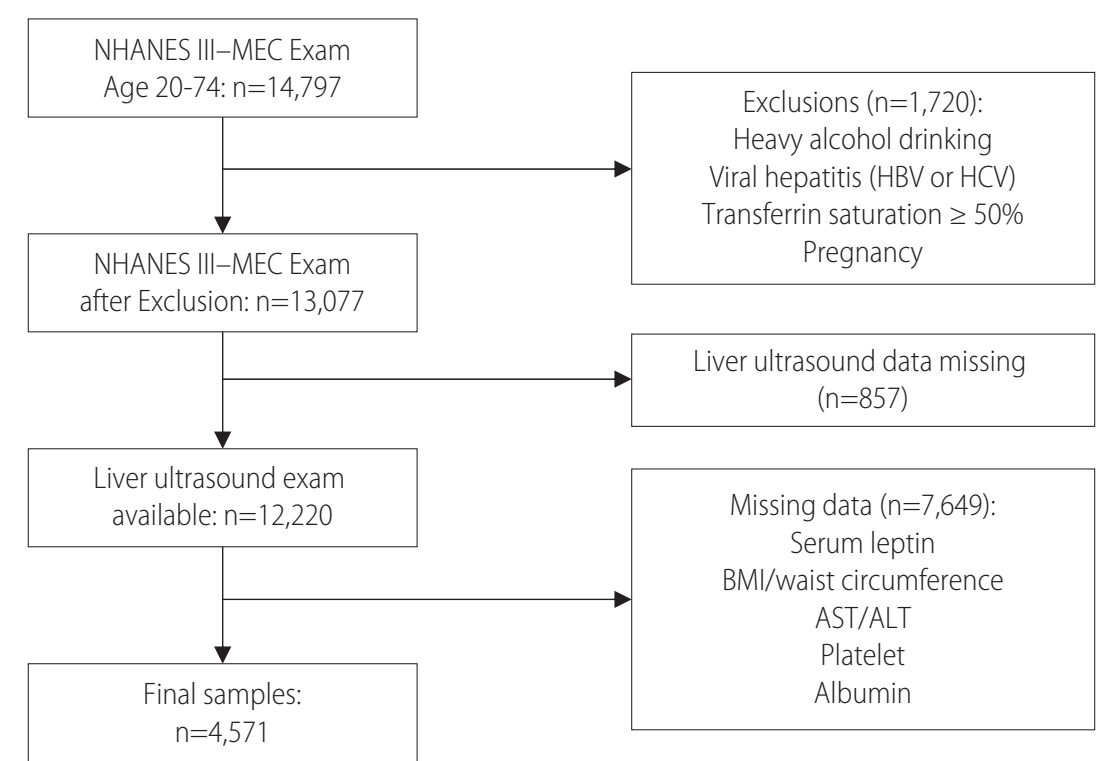

Figure 1. Selection criteria of the study population from the National Health and Nutrition Examination Survey III (NHANES III) database. MEC, Mobile Examination Center; HBV, hepatitis B virus; HCV, hepatitis C virus; BMl, body mass index; AST, aspartate aminotransferase; ALT, alanine aminotransferase. 
a score greater than 3.5 in the homeostasis model assessment of insulin resistance (HOMA-IR, calculated as (serum fasting glucose $x$ serum insulin)/22.5). ${ }^{26}$

Metabolic syndrome was characterized using the National Cholesterol Education Program Adult Treatment Panel (NCEP ATP III) definition. ${ }^{27}$ Serum leptin concentrations were measured using radioimmunoassay at Linco Research, Inc. (St. Charles, MO, USA). ${ }^{28}$

\section{Other covariates}

Demographic variables analyzed include age (measured as a continuous variable), sex (male or female), and race (non-Hispanic whites, non-Hispanic blacks, Hispanics and others). Smoking status was divided into the following categories: former, current or never smoker. Education level was denoted with binary characters (below college level vs. college or higher). Poverty index was categorized according to the poverty index guidelines ${ }^{29}$ with cut-offs of 1.3 and 1.85. Alcohol consumption was measured by number of drinks per week.

\section{Statistical analysis}

All data were analyzed using the 'survey' package in R software, version 3.2.2 (R studio, Boston, MA, USA). Frequencies of categorical variables and means with standard errors (SE) of continuous variables were analyzed. ${ }^{30}$ For all analyses, we used published weights to account for oversampling and nonparticipation in the household interview and physical examination to minimize a potential selection bias. In order to investigate the overall relationship between leptin and demographic variables, serum leptin levels were categorized into tertiles: low $(<5.9)$, intermediate (5.9-14.2), and high (>14.2 $\mu \mathrm{g} / \mathrm{L})$. Then, levels were analyzed by survey-weighted linear regression analysis, treating the each tertile group as ordinal variables to calculate trend $P$-values. Next, we used survey-weighted generalized linear regression to evaluate the association between serum leptin level and the degree of NAFLD. The degree of NAFLD based on ultrasound findings (normal, mild, moderate, and severe), NFS score group, and APRI score group was treated as an ordinal variable to calculate trend $P$-values. For subgroup analyses, we classified NAFLD into two groups by BMI (lean NAFLD: BMl<25 and classic NAFLD: BMI $\geq$ 25). Trend $P$-values were obtained both through unadjusted and adjusted models. The models were adjusted for age, gender and race in the limited model and further adjusted for hypertension, diabetes, waist-to-hip ratio, triglyceride (TG) level, high-density li- poprotein (HDL) level, and HOMA-IR score in the full model.

\section{RESULTS}

\section{Demographics}

Among 4,571 people who met our selection criteria and had all available information, 1,610 people (35\%) had NAFLD. Table 1 characterizes patient demographics according to serum leptin level by tertile. Leptin level was significantly higher in women than in men, with blacks being more prevalent in the highest leptin tertile. Compared to those individuals in the lowest tertile, those with higher leptin levels had a lower education level, higher BMI, larger waist circumference and were less often current smokers and had fewer alcoholic beverages a week. Those in the highest tertile were also more likely to have hypertension, diabetes, hyperlipidemia, and metabolic syndrome $(P$-value $<0.001)$. Higher leptin was also positively associated with HOMA-IR.

\section{Leptin level by degree of NAFLD as categorized by ultrasound}

Table 2 shows the relationship between serum leptin levels and the degree of NAFLD by ultrasound findings. There were 621 people with mild, 664 people with moderate, and 325 people with severe steatosis on ultrasound (Fig. 2). Leptin had a significant relationship with the degree of non-alcoholic fatty liver disease (for normal livers vs. mild, moderate and severe steatosis, levels were $10.7 \pm 0.3 \mathrm{ng} / \mathrm{mL}, 12.1 \pm 0.7 \mathrm{ng} / \mathrm{mL}, 15.6 \pm 0.8 \mathrm{ng} / \mathrm{mL}, 16 \pm 1.0 \mathrm{ng} / \mathrm{mL}$, respectively (trend $P$-value $<0.001$ ). This significant relationship persisted when adjusting for known demographic factors (limited model) that included age, gender, and race. However, this significance was no longer present after adjustments were made for metabolic risk factors that included: hypertension, diabetes, dyslipidemia, waist to hip ratio, metabolic syndrome, HOMA-IR score (full model). By further subgroup analysis breakdown according to BMI group (lean vs classic NAFLD), the association remained significant in the full model for the classic NAFLD group only $(14.7 \pm 0.5 \mathrm{ng} / \mathrm{mL}$ in normal, $16.1 \pm 1.1 \mathrm{ng} / \mathrm{mL}$ in mild, $17.8 \pm 0.8 \mathrm{ng} /$ $\mathrm{mL}$ in moderate, $16.9 \pm 1.1 \mathrm{ng} / \mathrm{mL}$ in severe steatosis, trend $P$-value<0.001). 
Table 1. Characteristics of patients according to serum leptin tertile

\begin{tabular}{|c|c|c|c|c|}
\hline & $\begin{array}{c}\text { Leptin 1st tertile } \\
\begin{array}{c}<5.9 \\
(n=1,523)\end{array}\end{array}$ & $\begin{array}{c}\text { 2nd tertile } \\
5.9-14.2 \\
(n=1,506)\end{array}$ & $\begin{array}{c}3 \text { rd tertile } \\
\quad>14.2 \\
(n=1,542)\end{array}$ & $\begin{array}{c}\text { Trend } \\
P \text {-value }\end{array}$ \\
\hline Age (years) & $40.0 \pm 0.4$ & $44.1 \pm 0.4$ & $46.1 \pm 0.3$ & $<0.01$ \\
\hline Gender (male \%) & $78.3 \pm 1.9$ & $40.3 \pm 1.8$ & $10.6 \pm 1.3$ & $<0.001$ \\
\hline Race (\%) & & & & $<0.01$ \\
\hline Non-Hispanic whites & $78.1 \pm 2.0$ & $77.7 \pm 2.1$ & $72.2 \pm 1.7$ & \\
\hline Non-Hispanic blacks & $8.7 \pm 0.8$ & $8.8 \pm 0.8$ & $14.9 \pm 1.1$ & \\
\hline Hispanics & $4.8 \pm 0.6$ & $5.0 \pm 0.5$ & $5.7 \pm 0.7$ & \\
\hline Others & $8.5 \pm 0.2$ & $8.5 \pm 0.2$ & $7.2 \pm 1.2$ & \\
\hline Education & & & & $<0.05(0.016)$ \\
\hline Below college level & $51.2 \pm 1.51$ & $53.4 \pm 1.67$ & $61.0 \pm 2.4$ & \\
\hline$\geq$ College level & $48.8 \pm 1.51$ & $46.6 \pm 1.67$ & $39.0 \pm 2.4$ & \\
\hline Poverty index ${ }^{\dagger}$ & & & & 0.23 \\
\hline$\leq 1.3$ & $16.3 \pm 2.0$ & $15.3 \pm 1.9$ & $18.2 \pm 1.5$ & \\
\hline $1.3-1.85$ & $9.1 \pm 1.1$ & $11.5 \pm 1.1$ & $11.7 \pm 1.1$ & \\
\hline$\geq 1.85$ & $74.6 \pm 2.5$ & $73.2 \pm 2.3$ & $70.1 \pm 2.1$ & \\
\hline Smoking status (\%) & & & & $<0.001$ \\
\hline Never & $39.8 \pm 2.1$ & $46.4 \pm 2.0$ & $55.1 \pm 1.9$ & \\
\hline Current & $35.1 \pm 1.6$ & $23.1 \pm 1.8$ & $18.9 \pm 1.4$ & \\
\hline Former & $25.1 \pm 1.5$ & $30.5 \pm 1.6$ & $26.0 \pm 1.8$ & \\
\hline Alcohol consumption (drinks/week) & $3.1 \pm 0.1$ & $2.5 \pm 0.1$ & $2.6 \pm 0.2$ & $<0.01$ \\
\hline $\mathrm{BMI}\left(\mathrm{kg} / \mathrm{m}^{2}\right)$ & $24.0 \pm 0.1$ & $26.0 \pm 0.2$ & $31.3 \pm 0.3$ & $<0.001$ \\
\hline Waist circumference (cm) & $86.6 \pm 0.6$ & $90.7 \pm 0.6$ & $100.5 \pm 0.6$ & $<0.001$ \\
\hline Waist to hip ratio & $0.91 \pm 0.004$ & $0.90 \pm 0.003$ & $0.90 \pm 0.004$ & 0.53 \\
\hline Hypertension (\%) & $14.4 \pm 1.1$ & $22.6 \pm 1.5$ & $30.9 \pm 2.1$ & $<0.001$ \\
\hline Diabetes (\%) & $2.8 \pm 0.5$ & $4.5 \pm 0.7$ & $5.6 \pm 0.9$ & $<0.001$ \\
\hline HOMA-IR & $1.8 \pm 0.1$ & $2.9 \pm 0.2$ & $3.9 \pm 0.2$ & $<0.001$ \\
\hline HbA1c (\%) & $5.2 \pm 0.03$ & $5.4 \pm 0.04$ & $5.4 \pm 0.04$ & 0.09 \\
\hline Triglyceride (TG) & $118 \pm 3.53$ & $144 \pm 5.00$ & $158 \pm 7.64$ & $<0.001$ \\
\hline $\mathrm{HDL}$ & $48.3 \pm 0.69$ & $50.1 \pm 0.51$ & $49.5 \pm 0.63$ & 0.18 \\
\hline Hyperlipidemia (\%) & $29.6 \pm 2.4$ & $37.7 \pm 2.1$ & $39.7 \pm 2.9$ & $<0.001$ \\
\hline Metabolic syndrome (\%) & $15.5 \pm 1.8$ & $29.8 \pm 1.7$ & $51.5 \pm 2.1$ & $<0.001$ \\
\hline
\end{tabular}

Values are presented as mean \pm SD unless otherwise indicated.

$\mathrm{BMI}$, body mass index; HOMA-IR, homeostatic model assessment for insulin resistance; HbA1c, hemoglobin A1c; TG, triglycerides; HDL, high density lipoprotein.

*Adjusted by age, sex, and race.

${ }^{\dagger}$ Poverty index was classified with cut-offs of 1.3 and 1.85 according to the poverty guidelines.

\section{Leptin level by degree of NAFLD as categorized by NFS}

There were 885 people with low NFS (<-1.455, consistent with lack of significant fibrosis), 596 people with intermediate NFS, and 129 people with high NFS $(>0.676$, indicative of advanced fibrosis) (Table 3, Fig. 3). Serum leptin levels for low, intermediate and high NFS were $11.8 \pm 0.5 \mathrm{ng} / \mathrm{mL}, 15.6 \pm 0.8 \mathrm{ng} / \mathrm{mL}, 28.5 \pm 3.5$ $\mathrm{ng} / \mathrm{mL}$, respectively (trend $P$-value $<0.001$ ). This association remained significant even after adjusting for known metabolic risk 
Table 2. Leptin level by degree of NAFLD on liver ultrasound findings

\begin{tabular}{|c|c|c|c|c|c|c|c|}
\hline & \multirow{2}{*}{$\begin{array}{l}\text { No NAFLD } \\
(n=2,961)\end{array}$} & \multicolumn{3}{|c|}{ NAFLD } & \multirow{2}{*}{$\begin{array}{c}\text { Unadjusted } \\
P \text {-value }\end{array}$} & \multirow{2}{*}{$\begin{array}{c}\text { Limited } \\
\text { model } \\
P \text {-value }\end{array}$} & \multirow{2}{*}{$\begin{array}{c}\text { Full model } \\
P \text {-value }\end{array}$} \\
\hline & & $\begin{array}{c}\text { Mild } \\
(n=621)\end{array}$ & $\begin{array}{c}\text { Moderate } \\
(n=664)\end{array}$ & $\begin{array}{l}\text { Severe } \\
(n=325)\end{array}$ & & & \\
\hline \multicolumn{8}{|l|}{ Leptin Level ( $\mu \mathrm{g} / \mathrm{L})$} \\
\hline Total & $10.7 \pm 0.30$ & $12.1 \pm 0.66$ & $15.6 \pm 0.75$ & $16.0 \pm 1.00$ & $<0.001$ & $<0.001$ & 0.48 \\
\hline Lean NAFLD (BMI<25) & $6.9 \pm 0.23$ & $7.0 \pm 0.40$ & $7.1 \pm 0.73$ & $7.6 \pm 1.02$ & 0.659 & 0.78 & 0.30 \\
\hline Classic NAFLD (BMI $\geq 25)$ & $14.7 \pm 0.48$ & $16.1 \pm 1.08$ & $17.8 \pm 0.83$ & $16.9 \pm 1.07$ & $<0.01$ & $<0.001$ & $<0.01$ \\
\hline
\end{tabular}

Values are presented as mean \pm SD unless otherwise indicated.

NAFLD, non-alcoholic fatty liver disease; BMI, body mass index.

*Adjusted for age, gender, race.

Adjusted for age, gender, race, hypertension, diabetes, waist to hip ratio, triglycerides, high density lipoprotein, homeostatic model assessment for insulin resistance.

Table 3. Leptin level by degree of NAFLD fibrosis score

\begin{tabular}{lcccccc}
\hline & $\begin{array}{c}\text { Low NFS } \\
(\mathbf{n}=\mathbf{8 8 5})\end{array}$ & $\begin{array}{c}\text { Intermediate NFS } \\
(\mathbf{n}=596)\end{array}$ & $\begin{array}{c}\text { High NFS } \\
(\mathbf{n = 1 2 9})\end{array}$ & $\begin{array}{c}\text { Unadjusted } \\
\boldsymbol{P} \text {-value }\end{array}$ & $\begin{array}{c}\text { Limited model } \\
\boldsymbol{P} \text {-value }\end{array}$ & $\begin{array}{c}\text { Full model } \\
\boldsymbol{P}^{*} \text {-value }\end{array}$ \\
\hline Leptin Level $(\mu \mathrm{g} / \mathrm{L})$ & & & & & & \\
\hline Total & $11.8 \pm 0.53$ & $15.6 \pm 0.79$ & $28.5 \pm 3.48$ & $<0.001$ & $<0.001$ & $<0.001$ \\
Lean NAFLD $(\mathrm{BM}<<25)$ & $6.7 \pm 0.36$ & $7.6 \pm 1.22$ & $5.4 \pm 0.80$ & 0.53 & 0.82 & 0.19 \\
Classic NAFLD $(\mathrm{BMl} \geq 25)$ & $15.7 \pm 0.70$ & $16.6 \pm 0.84$ & $28.2 \pm 3.30$ & $<0.001$ & $<0.001$ & $<0.001$ \\
\hline
\end{tabular}

Values are presented as mean \pm SD unless otherwise indicated.

NAFLD, non-alcoholic fatty liver disease; NFS, non-alcoholic fatty liver disease fibrosis score; BMI, body mass index.

*Adjusted for age, gender, race.

${ }^{\dagger}$ Adjusted for age, gender, race, hypertension, diabetes, waist to hip ratio, triglycerides, high density lipoprotein, homeostatic model assessment for insulin resistance.

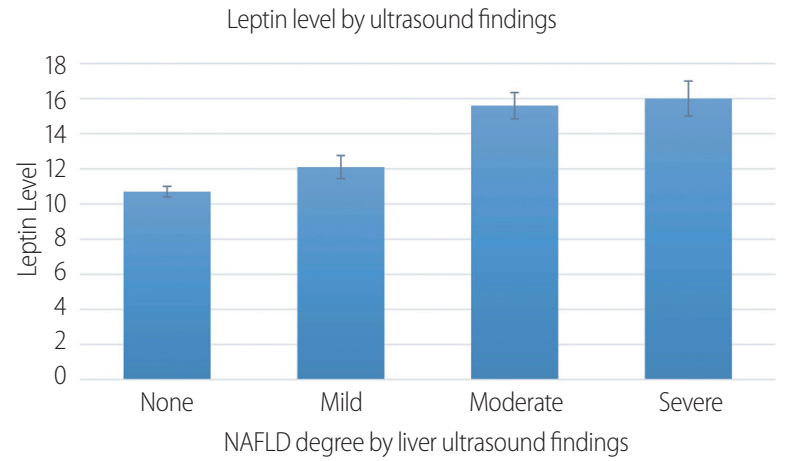

Figure 2. Leptin level by degree of non-alcoholic fatty liver disease (NAFLD) based on liver ultrasound findings with 95\% confidence intervals.

factors (age, sex, race, hypertension, diabetes, HOMA-IR, waist to hip ratio, and metabolic syndrome). In subgroup analysis by BMI group, the association was only prominent in the classic NAFLD $(15.7 \pm 0.70 \mathrm{ng} / \mathrm{mL}$ in low NFS, $16.6 \pm 0.84 \mathrm{ng} / \mathrm{mL}$ in intermediate $\mathrm{NFS}, 28.2 \pm 3.30 \mathrm{ng} / \mathrm{mL}$ in high NFS, trend $P$-value $<0.001$ ), but not in lean NAFLD. A similar trend was observed when we used APRI score instead of NFS (Supplementary Table 1).

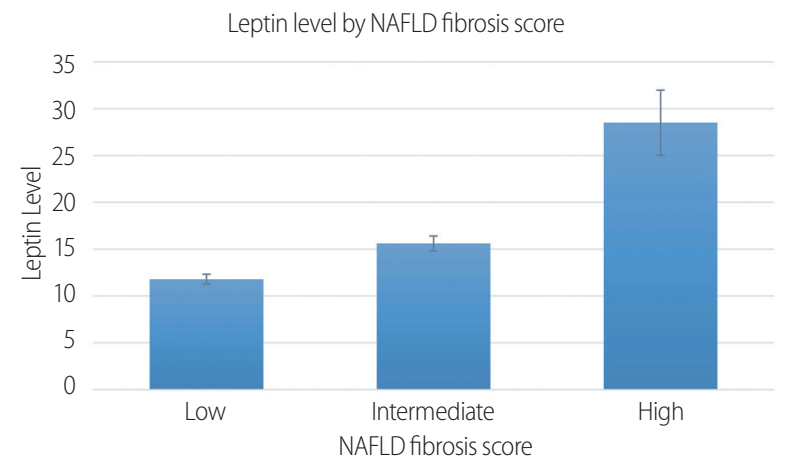

Figure 3. Leptin level based on non-alcoholic fatty liver disease (NAFLD) fibrosis score with 95\% confidence intervals.

\section{DISCUSSION}

NAFLD affects nearly $25 \%$ of the general population globally. ${ }^{10}$ Obese populations are specifically targeted, with $57.5-74 \%$ of the adult population affected and even $22.5-52.8 \%$ of obese children showing evidence of NAFLD. ${ }^{10,31}$ It has been proposed that the finding of fibrosis in nonalcoholic fatty liver disease suggests a 
progressive course of liver injury. ${ }^{31}$ Our study examined the association between leptin levels and non-alcoholic fatty liver disease and found that a higher leptin level was associated with increased hepatic steatosis severity based on both ultrasound findings and NAFLD fibrosis score. This finding remained significant after adjusting for known demographic variables only in classic NAFLD, which suggests that leptin's role in NAFLD pathogenesis may be BMI-dependent.

It is interesting that with increasing levels of serum leptin, nonHispanic blacks and Hispanics constitute a greater percentage of the cohort. Given that obesity, diabetes, and metabolic syndrome are more prevalent among Hispanics and African Americans, ${ }^{32-34}$ this association can contribute to the increased risk seen for developing NAFLD. Our study also found that the highest leptin tertile had more women when compared to other tertiles. This may be in part due to the effect of hormones, ${ }^{35}$ percentage of adipose tissue $^{36}$ dietary differences ${ }^{32}$ and perimenopausal age, which may enhance metabolic syndrome risk factors and contribute to a higher incidence in women. Furthermore, in the non-alcoholic steatohepatitis Clinical Research Network database, women outnumbered men 2:1, ${ }^{37}$ similar to our study results. Selthofer-Relatić et al. showed that the leptin-to-adiponectin ratio was higher in females compared to males and that this finding was associated with higher visceral obesity. ${ }^{38}$ Another study has found that after adjusting for body fat, woman had higher leptin levels than men. ${ }^{39}$ This finding could be related to estrogen's role on leptin expression as one study's finding ${ }^{40}$ suggest that leptin levels decrease in women after menopause while the mean values of BMI, insulin and HOMAIR score remained unchanged by menopause status. Individuals with the highest leptin levels were also more likely to have hypertension, diabetes, hyperlipidemia, and metabolic syndrome.

Leptin is thought to increase hepatic steatosis, inflammation and fibrosis. ${ }^{41}$ Leptin augments the development of insulin resistance and has a pro-inflammatory role that contributes to the development of fibrosis. ${ }^{41}$ In part, this is due to the promotion of expression of a2 (I) collagen and its excessive deposition in the liver. ${ }^{16}$ Insulin resistance and hyperinsulinemia elevates serum free fatty acid levels, which in turn increases triglyceride production and hepatic steatosis. ${ }^{42}$ Chronic insulin resistance also results in hepatic lipogenesis and has been thought to stimulate pro-fibrotic cytokines. ${ }^{42,43}$ It is possible that through this mechanism of increased insulin resistance, inflammation and collagen deposition, leptin contributes to the development of NAFLD in overweight individuals that are at a higher risk for metabolic syndrome.

It has been previously shown ${ }^{44}$ that in those with lean NAFLD, the fasting glucose and HbA1c were lower and associated with less fibrosis when compared to classic NAFLD. This might suggest that the mechanism in lean individuals is through a pathway independent of leptin-driven fibrosis, which leads to the development of metabolic syndrome as an intermediate step towards NAFLD. A prior study has shown that lean NAFLD patients had lower prevalence of diabetes, hypertension, hypertriglyceridemia and metabolic syndrome. ${ }^{12}$ However, the overall mortality was higher in lean NAFLD patients. ${ }^{12}$ In the lean NAFLD population, certain genetic factors were thought to contribute to the development of liver steatosis, including hypobetalipoproteinemia ${ }^{45}$ and malabsorption disorders such as celiac disease ${ }^{46,47}$ and cystic fibrosis. ${ }^{48}$ In spite of these individuals developing severe steatosis, they have not been shown to have reduced insulin sensitivity. ${ }^{45,49}$ These individuals were associated with elevated transaminases. ${ }^{49}$ When compared to obese populations, those with lean NAFLD have significantly less fibrosis and inflammation ${ }^{44,50}$ but were found to have more severe lobular inflammation. ${ }^{12}$

In our study, there was a clear trend showing that with increased liver fibrosis there were similar rises in leptin levels, seen most significantly with elevated BMI $(P<0.001)$. Several in vivo and ex vivo studies have attested to this profibrogenic role of leptin. ${ }^{2}$ Other data demonstrate that Kupffer cells and sinusoidal endothelial cells contain leptin receptors that increase matrix remodeling gene expression, which initiates the cascade of fibrosis in hepatic stellate cells (HSCS). ${ }^{51}$ Other studies ${ }^{2,16}$ show HSCs are directly targeted by leptin itself to modulate signal transduction systems and fibrotic gene expression as well as to promote the persistence of HSCs in the activated phase, thus stimulating proliferation and furthering fibrogenesis. ${ }^{6}$ However, the exact mechanisms of fibrogenesis have yet to be fully determined.

Moreover, on ultrasonography of the liver in NAFLD, there is an increase in echogenicity caused by fatty infiltration (steatosis), ${ }^{52}$ as well as additional findings of hepatocyte ballooning, necrosis, and Mallory's hyaline on biopsy. ${ }^{53,54}$ Additionally, it has been previously shown ${ }^{55}$ that the severity of liver histologic changes, such as findings of advanced fibrosis, at the time of diagnosis plays a prognostic role in the progression towards developing cirrhosis further demonstrating the destructive effects of NAFLD. Similar to the aforementioned fibrosis trend, our comparisons demonstrated that increased hepatic steatosis correlates with elevations in leptin, especially at a higher BMI.

Finding a potential marker associated with disease severity is important given the high prevalence of NAFLD and its elevated risk of complications. Prior studies have shown that people with 
Laura Rotundo, et al.

Leptin level by severity of NAFLD

NAFLD had increased mortality compared to the general population; -their top two leading causes of death were malignancy and ischemic heart disease, with liver related mortality being the third leading cause of death. ${ }^{56,57}$

A strength of our study is that the findings are based on nationally representative data in the United States that include comprehensive demographic information, laboratory tests, physical examination results, and a clinical questionnaire. While a previous study $^{58}$ has shown the positive relationship of leptin with NAFLD, our study went further to examine separately for the severity of fibrosis stage in NAFLD patients and found that the serum leptin level was significantly associated with increased fibrosis severity. Furthermore, we strongly believe that it is still important to investigate national population data to confirm the association between leptin and NAFLD since the evidence in existing literature is still conflicting. Limitations include the fact that NAFLD was not diagnosed by liver biopsy. In this study, NAFLD was assessed by histological criteria on the basis of liver ultrasound findings, which has previously been demonstrated to have a specificity of $100 \%$ and sensitivity of $83 \%{ }^{59}$ A non-invasive diagnostic tool, such as ultrasound, may be a more appropriate screening method in a large epidemiological study and has been previously shown to have good screening accuracy. ${ }^{60}$ Lastly, given the cross-sectional design of this study, we could not disclose if there was a causal relationship between leptin and NAFLD.

In conclusion, higher serum leptin level is associated with NAFLD. Moreover, the serum concentration of leptin correlates with severity of hepatic steatosis, especially in classic (high BMI) NAFLD patients. Future prospective studies are warranted to further investigate these findings in order to gain insight on the role of leptin level in predicting NAFLD severity.

\section{Authors' contribution}

Study design: L. Rotundo, H.S. Kim

Acquisition, analysis and interpretation of data: All authors

Drafting of the manuscript: All authors

Critical revision of the manuscript: All authors

Statistical analysis: H.S. Kim

Study supervision: H.S. Kim, L. Rotundo

\section{Conflicts of Interest}

The authors certify that they have no affiliations with or involvement in any organization or entity with any financial interest or non-financial interest in the subject matter or materials discussed in this manuscript.

\section{SUPPLEMENTARY MATERIALS}

Supplementary materials are available at Clinical and Molecular Hepatology website (http://www.e-cmh.org).

\section{REFERENCES}

1. Fantuzzi G, Faggioni R. Leptin in the regulation of immunity, inflammation, and hematopoiesis. J Leukoc Biol 2000;68:437-446.

2. Angulo P, Alba LM, Petrovic LM, Adams LA, Lindor KD, Jensen MD. Leptin, insulin resistance, and liver fibrosis in human nonalcoholic fatty liver disease. J Hepatol 2004;41:943-949.

3. Testa R, Franceschini R, Giannini E, Cataldi A, Botta F, Fasoli A, et al. Serum leptin levels in patients with viral chronic hepatitis or liver cirrhosis. J Hepatol 2000;33:33-37.

4. Bouloumie A, Marumo T, Lafontan M, Busse R. Leptin induces oxidative stress in human endothelial cells. FASEB J 1999;13:1231 1238.

5. Ikejima K, Honda H, Yoshikawa M, Hirose M, Kitamura T, Takei Y, et al. Leptin augments inflammatory and profibrogenic responses in the murine liver induced by hepatotoxic chemicals. Hepatology 2001;34:288-297.

6. Saxena NK, Titus MA, Ding X, Floyd J, Srinivasan S, Sitaraman SV, et al. Leptin as a novel profibrogenic cytokine in hepatic stellate cells: mitogenesis and inhibition of apoptosis mediated by extracellular regulated kinase (Erk) and Akt phosphorylation. FASEB 2004;18:1612-1614.

7. Bedogni G, Miglioli L, Masutti F, Tiribelli C, Marchesini G, Bellentani $S$. Prevalence of and risk factors for nonalcoholic fatty liver disease: the Dionysos nutrition and liver study. Hepatology 2005;42:44-52.

8. Neuschwander-Tetri BA, Caldwell SH. Nonalcoholic steatohepatitis: summary of an AASLD Single Topic Conference. Hepatology 2003;37:1202-1219.

9. Lazo M, Clark JM. The epidemiology of nonalcoholic fatty liver disease: a global perspective. Semin Liver Dis 2008;28:339-350.

10. Younossi ZM, Koenig AB, Abdelatif D, Fazel Y, Henry L, Wymer M. Global epidemiology of nonalcoholic fatty liver disease-Meta-analytic assessment of prevalence, incidence, and outcomes. Hepatology 2016;64:73-84.

11. Kim HJ, Kim HJ, Lee KE, Kim DJ, Kim SK, Ahn CW, et al. Metabolic significance of nonalcoholic fatty liver disease in nonobese, nondiabetic adults. Arch Intern Med 2004;164:2169-2175.

12. Cruz ACD, Bugianesi E, George J, Day CP, Liaquat H, Charatcharoenwitthaya $P$, et al. 379. Characteristics and long-term prognosis of lean patients with nonalcoholic fatty liver disease [Abstract]. Gastroenterology 2014;146:S-909.

13. Uygun A, Kadayifci A, Yesilova Z, Erdil A, Yaman H, Saka M, et al. 
Serum leptin levels in patients with nonalcoholic steatohepatitis. Am J Gastroenterol 2000;95:3584-3589.

14. Dasarathy S, Yang Y, McCullough AJ, Marczewski S, Bennett C, Kalhan SC. Elevated hepatic fatty acid oxidation, high plasma fibroblast growth factor 21, and fasting bile acids in nonalcoholic steatohepatitis. Eur J Gastroenterol Hepatol 2011;23:382-388.

15. Saxena NK, Ikeda K, Rockey DC, Friedman SL, Anania FA. Leptin in hepatic fibrosis: evidence for increased collagen production in stellate cells and lean littermates of ob/ob mice. Hepatology 2002:35:762-771.

16. Saxena NK, Saliba G, Floyd JJ, Anania FA. Leptin induces increased alpha2(I) collagen gene expression in cultured rat hepatic stellate cells. J Cell Biochem 2003;89:311-320.

17. Elbadawy RA, Eleter EA, Helmy A, Al Ghamdi AS, Al-Mofleh I, Al Faleh $\mathrm{FZ}$, et al. The role of leptin in non-alcoholic fatty liver disease. Saudi J Gastroenterol 2006;12:68-72.

18. Chitturi S, Farrell G, Frost L, Kriketos A, Lin R, Fung C, et al. Serum leptin in NASH correlates with hepatic steatosis but not fibrosis: a manifestation of lipotoxicity? Hepatology 2002;36:403-409.

19. Chalasani N, Crabb DW, Cummings OW, Kwo PY, Asghar A, Pandya PK, et al. Does leptin play a role in the pathogenesis of human nonalcoholic steatohepatitis? Am J Gastroenterol 2003;98:2771-2776.

20. National Center for Health Statistics (NCHS). Plan and Operation of the Third National Health and Nutritional Examination Survey, 1988-94. Series 1: Programs and Collection Procedures. NCHS web site, <https://www.cdc.gov/nchs/data/series/sr_01/sr01_032.pdf>. Accessed 11 Nov 2017.

21. Kim D, Kim WR, Kim HJ, Therneau TM. Association between noninvasive fibrosis markers and mortality among adults with nonalcoholic fatty liver disease in the United States. Hepatology 2013;57:13571365.

22. Angulo P, Hui JM, Marchesini G, Bugianesi E, George J, Farrell GC, et al. The NAFLD fibrosis score: a noninvasive system that identifies liver fibrosis in patients with NAFLD. Hepatology 2007;45:846-854.

23. Lin ZH, Xin YN, Dong QJ, Wang Q, Jiang XJ, Zhan SH, et al. Performance of the aspartate aminotransferase-to-platelet ratio index for the staging of hepatitis C-related fibrosis: an updated meta-analysis. Hepatology 2011;53:726-736.

24. National Center for Health Statistics (NCHS). National Health and Nutrition Examination Survey III: Body Measurements (Anthropometry). NCHS web site, <https://www.cdc.gov/nchs/nhanes/nh3rrm. htm>. Accessed 11 Nov 2017.

25. National Center for Health Statistics (NCHS). Laboratory Procedures Used for the Third National Health and Nutrition Examination Survey (NHANES III), 1988-1994. 1996. NCHS web site, <https://www.cdc. gov/nchs/nhanes/nh3rrm.htm>. Accessed 11 Nov 2017.

26. Liangpunsakul S, Chalasani N. Serum vitamin D concentrations and unexplained elevation in ALT among US adults. Dig Dis Sci
2011;56:2124-2129.

27. Expert Panel on Detection, Evaluation, and Treatment of High Blood Cholesterol in Adults. Executive summary of the Third Report of the National Cholesterol Education Program (NCEP) expert panel on detection, evaluation, and treatment of high blood cholesterol in adults (Adult Treatment Panel III). JAMA 2001;285:2486-2497.

28. Ma Z, Gingerich RL, Santiago JV, Klein S, Smith CH, Landt M. Radioimmunoassay of leptin in human plasma. Clin Chem 1996;42(6 Pt 1):942-946.

29. National Center for Health Statistics (NCHS). 2013-2014 Data Documentation, Codebook, and Frequencies. 2015. NCHS web site, $<$ https://www.cdc.gov/nchs/nis/data_files.htm>. Accessed $11 \mathrm{Nov}$ 2017.

30. Lumley T. Analysis of complex survey samples. J Statistic Software 2004;9:1-19.

31. Angulo P. Nonalcoholic fatty liver disease. N Engl J Med 2002;346:12211231.

32. Campbell B, Aguilar M, Bhuket T, Torres S, Liu B, Wong RJ. Females, Hispanics and older individuals are at greatest risk of developing metabolic syndrome in the US. Diabetes Metab Syndr 2016;10:230-233.

33. Crespo CJ, Loria CM, Burt VL. Hypertension and other cardiovascular disease risk factors among Mexican Americans, Cuban Americans, and Puerto Ricans from the Hispanic Health and Nutrition Examination Survey. Public Health Rep 1996;111 Suppl 2:7-10.

34. Brancati FL, Kao WH, Folsom AR, Watson RL, Szklo M. Incident type 2 diabetes mellitus in African American and white adults: the Atherosclerosis Risk in Communities Study. JAMA 2000;283:2253-2259.

35. Targher G, Rossini M, Lonardo A. Evidence that non-alcoholic fatty liver disease and polycystic ovary syndrome are associated by necessity rather than chance: a novel hepato-ovarian axis? Endocrine 2016;51:211-221.

36. Ayonrinde OT, Olynyk JK, Beilin LJ, Mori TA, Pennell CE, de Klerk $N$, et al. Gender-specific differences in adipose distribution and adipocytokines influence adolescent nonalcoholic fatty liver disease. Hepatology 2011;53:800-809.

37. Neuschwander-Tetri BA, Clark JM, Bass NM, Van Natta ML, UnalpArida A, Tonascia J, et al. Clinical, laboratory and histological associations in adults with nonalcoholic fatty liver disease. Hepatology 2010;52:913-924.

38. Selthofer-Relatić K, Radić R, Stupin A, Šišljagić V, Bošnjak I, Bulj N, et al. Leptin/adiponectin ratio in overweight patients - gender differences. Diab Vasc Dis Res 2018;15:260-262.

39. Liuzzi A, Savia G, Tagliaferri M, Lucantoni R, Berselli ME, Petroni $M L$, et al. Serum leptin concentration in moderate and severe obesity: relationship with clinical, anthropometric and metabolic factors. Int J Obes Relat Metab Disord 1999;23:1066-1073.

40. Ben Ali S, Jemaa R, Ftouhi B, Kallel A, Feki M, Slimene H, et al. Relationship of plasma leptin and adiponectin concentrations with 
menopausal status in Tunisian women. Cytokine 2011;56:338-342.

41. Tsochatzis EA, Papatheodoridis GV, Archimandritis AJ. Adipokines in nonalcoholic steatohepatitis: from pathogenesis to implications in diagnosis and therapy. Mediators Inflamm 2009;2009:831670.

42. Lewis GF, Carpentier A, Adeli K, Giacca A. Disordered fat storage and mobilization in the pathogenesis of insulin resistance and type 2 diabetes. Endocr Rev 2002;23:201-229.

43. Paradis V, Perlemuter G, Bonvoust F, Dargere D, Parfait B, Vidaud $M$, et al. High glucose and hyperinsulinemia stimulate connective tissue growth factor expression: a potential mechanism involved in progression to fibrosis in nonalcoholic steatohepatitis. Hepatology 2001;34(4 Pt 1):738-744.

44. Vos B, Moreno C, Nagy N, Féry F, Cnop M, Vereerstraeten $P$, et al. Lean non-alcoholic fatty liver disease (Lean-NAFLD): a major cause of cryptogenic liver disease. Acta Gastroenterol Belg 2011;74:389-394.

45. Visser ME, Lammers NM, Nederveen AJ, van der Graaf M, Heerschap A, Ackermans MT, et al. Hepatic steatosis does not cause insulin resistance in people with familial hypobetalipoproteinaemia. Diabetologia 2011;54:2113-2121.

46. Rahimi AR, Daryani NE, Ghofrani H, Taher M, Pashaei MR, Abdollahzade $S$, et al. The prevalence of celiac disease among patients with non-alcoholic fatty liver disease in Iran. Turk J Gastroenterol 2011;22:300-304.

47. Abenavoli L, Milic N, De Lorenzo A, Luzza F. A pathogenetic link between non-alcoholic fatty liver disease and celiac disease. Endocrine 2013;43:65-67.

48. Staufer K, Halilbasic E, Trauner M, Kazemi-Shirazi L. Cystic fibrosis related liver disease--another black box in hepatology. Int J Mol Sci 2014;15:13529-13549.

49. Margariti E, Deutsch M, Manolakopoulos S, Papatheodoridis GV. Non-alcoholic fatty liver disease may develop in individuals with normal body mass index. Ann Gastroenterol 2012;25:45-51.

50. Kumar R, Rastogi A, Sharma MK, Bhatia V, Garg H, Bihari C, et al. Clinicopathological characteristics and metabolic profiles of non- alcoholic fatty liver disease in Indian patients with normal body mass index: do they differ from obese or overweight non-alcoholic fatty liver disease? Indian J Endocrinol Metab 2013;17:665-671.

51. Ikejima K, Lang T, Zhang YJ, Yamashina S, Honda H, Yoshikawa M, et al. Expression of leptin receptors in hepatic sinusoidal cells. Comp Hepatol 2004;3 Suppl 1:S12.

52. Joseph AE, Saverymuttu S, al-Sam S, Cook MG, Maxwell JD. Comparison of liver histology with ultrasonography in assessing diffuse parenchymal liver disease. Clin Radiol 1991;43:26-31.

53. Brunt EM. Nonalcoholic steatohepatitis: definition and pathology. Semin Liver dis 2001;21:3-16.

54. Brunt EM, Janney CG, Di Bisceglie AM, Neuschwander-Tetri BA, Bacon BR. Nonalcoholic steatohepatitis: a proposal for grading and staging the histological lesions. Am J Gastroenterol 1999;94:2467-2474.

55. Puustinen L, Boyd S, Mustonen H, Arkkila P, Arola J, Färkkilä M. Prognostic value of clinical variables and liver histology for development of fibrosis and cirrhosis in autoimmune hepatitis. Scand J Gastroenterol 2017;52:321-327.

56. Adams LA, Lymp JF, St Sauver J, Sanderson SO, Lindor KD, Feldstein $A$, et al. The natural history of nonalcoholic fatty liver disease: a population-based cohort study. Gastroenterology 2005;129:113-121.

57. Ong JP, Pitts A, Younossi ZM. Increased overall mortality and liverrelated mortality in non-alcoholic fatty liver disease. J Hepatol 2008:49:608-612.

58. Polyzos SA, Aronis KN, Kountouras J, Raptis DD, Vasiloglou MF, Mantzoros CS. Circulating leptin in non-alcoholic fatty liver disease: a systematic review and meta-analysis. Diabetologia 2016;59:30-43.

59. Saverymuttu SH, Joseph AE, Maxwell JD. Ultrasound scanning in the detection of hepatic fibrosis and steatosis. Br Med J (Clin Res Ed) 1986;292:13-15.

60. Hernaez R, Lazo M, Bonekamp S, Kamel I, Brancati FL, Guallar E, et al. Diagnostic accuracy and reliability of ultrasonography for the detection of fatty liver: a meta-analysis. Hepatology 2011;54:10821090. 